\title{
Gastro-Özofageal Hastalık Ilișkili Distoni: Sandifer Sendromu
}

\section{Gastroesophageal Reflux Disease Associated Dystonia: Sandifer Syndrome}

\author{
Hande Gazeteci Tekin, Gül Serdaroğlu, Sarenur Gökben \\ Ege Üniversitesi Tıp Fakültesi, Pediatrik Nöroloji Bilim Dalı, Izmir, Türkiye
}

\begin{abstract}
ÖZET
Sandifer sendromu Gastro-Özofageal Reflü hastalığı (GÖRH) ilişkili paroksismal hareket bozukluğudur. Genellikle mental-motor gelişimin normal olduğu görülür. Çoğu olgu çocuktur ve semptomlar erken çocukluk yaş grubunda başlar. Erken çocukluk yaş grubunda çoğunlukla opistotonik postür, retrokollis ve istenmeyen baş hareketleri gözlenir. Tedavide antireflü tedavi ya da funduplikasyon Sandifer sendromunda kullanılmaktadır. Gastro-Özofageal Reflü hastalığına bağı hareket bozukluğu tanımlayan üç yaşındaki olgu sunulmuştur. The Journal of Pediatric Research 2014;1(2):99-100

Anahtar Kelimeler: Gastro-Özofagial Reflü hastalığı, distoni, hareket bozukluğu, Sandifer sendromu
\end{abstract}

\section{ABSTRACT}

Sandifer syndrome is a paroxysmal movement disorder in association with Gastroesophageal Reflux disease (GERD). In generally mental-motor development is normal. Most cases are children with symptom onset in early childhood. In early childhood usually have opisthotonic posture, retrocollis and unvoluntery head movements. Anti-reflux medications and/or funduplication is used in the treatment of Sandifer syndrome. We present a 3-year-old male who has movements disorder caused by GERD. The Journal of Pediatric Research 2014;1(2):99-100

Key Words: Gastroesophageal Reflux disease, dystonia, movements disorder, Sandifer syndrome

\section{Giriş}

Sandifer sendromu ilk kez 1964 yılında üst gastrointestinal sistem hastalıkları ile birliktelik gösteren baş ve boyundaki anormal hareketler olarak M. Kinsbourne tarafından tanımlanmıştır. Sendrom adını araştırmacıya yardımcı olan Dr. Paul Sandifer'den almıştır (1). Daha çok infantlarda ve süt çocuklarında gözlenen ve Gastro-Özofageal Reflü (GÖRH) ile olan ilişkisi litaratürde tanımlanmış, baş ve boyundaki distonik hareketlerle karakterizedir (2). Bu yazıda 3 yaşında özafagial atrezi nedeniyle operasyon öyküsü olan GÖRH kontrol altına alınamamış ve distonik hareketleri olan bir olgu sunulmuştur.

\section{Olgu Sunumu}

Üç yaş erkek hasta, iki aydır, günde 10-15 kez olan, birkaç saniye süren başını ve boynunu sağ yana çevirme, o sırada bir noktaya sabit bakma ve kasılma yakınması ile getirildi. Hastanın özofagus atrezisi nedeniyle dört kez operasyon geçirdiği, halen beslenme esnasında ve hemen sonrasında bulantı ve kusma şikayetlerinin olduğu bu sebeple değişik zaman aralıkları ile domperidon, proton pompa inhibitörü, ranitidin, magnezyum aljinat kullandığı son iki aydır bu yakınmalarının olduğu öğrenildi. Olgu bu dönemde yalnız domperidon tedavisi almaktaydı. Fizik bakıda ağırlığı 12,3 kg (3-10 p), boyu $91 \mathrm{~cm}$ (10-25 p), baş çevresi $49 \mathrm{~cm}$ (25-50 
p) göğüste geçirilmiş operasyona ikincil skar dışında özellik yoktu. Hemogram, biyokimya ve B12 vitamin düzeyleri normal saptandı. Hastanın muayenesi esnasında bahsedilen kasılmalar gözlendi. Video-Elektroensefalografi (EEG) monitorizasyonunda, çekim esnasında kasılmaları gözlendi ancak EEG'de eşlik eden epileptiform deşarj gözlenmedi. Yalnız hareket artefaktları izlendi. Olgu klinik video EEG bulguları ile Sandifer sendromu olarak değerlendirildi ve anti reflü tedavisi proton pompa inhibitörü olarak değiştirildi. On gün sonraki değerlendirmede, hastanın kasılma ve kusma sayısında belirgin azalma olduğu öğrenildi.

\section{Tartışma}

Istemdışı hareket bozuklukları (distoni veya koreatetoz) tik bozuklukları, motor bulgular nedeniyle sıkça epilepsi ile karışabilir. Ayırıcı tanıda, öykü, ayrıntılı klinik ve nörolojik değerlendirme, motor fenomenin görülmesi ve video EEG monitorizasyon yardımcıdır (3). Nöbet şüphesi ile ileri değerlendirme yapılan hastaların dörtte birinde paroksismal epileptik olmayan durumlar saptanmaktadır (4).

Sandifer sendromu nadir görülen, genellikle tortikolis ve distonik vücut hareketlerinin eşlik ettiği GÖRH veya hiatal herni birlikteliği ile görülen bir durumdur $(5,6)$. Hastalar sıklıkla beslenme problemleri, kusma ve bunlara bağlı demir eksikliği anemisi ile başvurur $(7,8)$. Sandifer sendromunun patofizyolojisi bilinmemektedir. Boynun kontraksiyon hareketi ile alt özofagustaki asit maruziyetinin anatomik olarak yer değiştirmesi ve sürekli maruziyetin verdiği yanma hissinin azalmış olabileceği, bir diğer açıklamaysa bu hareketin hava yolunu, buraya ulaşabilecek reflüden korumak için yapılmış olabileceğidir (9-11). Erken tanı alan olgularda tedavi başarıı olmakta, nörolojik açıdan ileri değerlendirme için gereksiz maliyet ve iş gücü kaybı önlenmektedir. Tedavide domperidon, metokloropomid, proton pompa inhibitörleri kullanılır (11-13). Olgumuzda daha önce kullanmış olduğu medikal tedavi ile gözlenmeyen distonik hareketler, medikal tedaviden fayda görmesi üzerine çoklu ilaç kullanımı azaltııma aşamasında iken yeniden ortaya çıkmıştır. Kusma ve bulantılarının artması ile ortaya çıkan bu durum yine proton pompa inhibitörünün tedaviye eklenmesi ile azalmıştır.

\section{Sonuç}

Epileptik olmayan paroksismal olaylar nöbet ya da diğer nörolojik tanılar ile karışıklığa neden olabilmektedir. Hastalardan alınan iyi bir anemnez ve mevcut anormal hareketlerin video görüntülerinin izlenmesi gereksiz tetkiklerin yapılmasını önlemektedir. Hastamızda olduğu gibi, gastrointestinal sistem ağırlıklı yakınmaları ve özgeçmişinde bu sisteme ait girişim öyküsü olan hastalarda, baş ve boyundaki istem dışı hareketlerin ayırıcı tanısında Sandifer sendromu öncelikle düşünülmelidir.

\section{Kaynaklar}

1. Kinsbourne M. Hiatus hernia with contortions of the neck. Lancet 1964; 13: 1058-61.

2. Frankel EA, Shalaby TM, Orenstein SR. Sandifer syndrome posturing: relation to abdominal wall contractions, gastroesophagealreflux, and fundoplication. Dig Dis Sci 2006; 51: 635-40

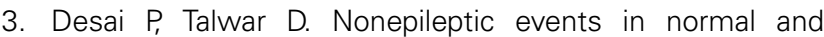
neurologically handicapped children: a video-EEG study. Pediatr Neurol 1992; 8: 127-9.

4. Paolicchi JM. The spectrum of nonepileptic events in children. Epilepsia 2002; 43(Suppl3): 60-4.

5. Sutcliffe J. Torsion spasms and abnormal postures in children with hiatus hernia: Sandifer's syndrome. Prog Pediatr Radiol 1969; 2: 190-7.

6. Werlin SL, D'Souza BJ, Hogan WJ, Dodds WJ, Arndorfer RC. Sandifer syndrome: an unappreciated clinical entity. Dev Med Child Neurol 1980; 22: 374-8.

7. Corrado G, Cavaliere M, D'Eufemia P, Pelliccia A, Celli M, Porcelli M, Giardini O, Cardi E. Sandifer's syndrome in a breast-fed infant. Am J Perinatol 2000; 17: 147-50.

8. Puntis JWL, Smith HL, Buick RG. Effect of dystonic movements on oesophageal peristalsis in Sandifer's syndrome reported and reviewed. Pediatr Surg Int 1991; 6: 210-3.

9. Deskin RW. Sandifer syndrome: a cause of torticollis ininfancy. Int J Pediatr Otorhinolaryngol 1995; 32: 183-5.

10. Nanayakkara CS, Paton JY. Sandifer syndrome: an overlooked diagnosis? Dev Med Child Neurol 1985; 27: 816-9.

11. Gorrotxategi P, Reguilon MJ, Arana J, Gaztanaga R, Elorza C, de la Iglesia E, Barriola M. Gastroesophageal reflux in association with the Sandifer syndrome. Eur J Pediatr Surg 1995; 5: 203-5.

12. Loureiro $B$, Ferrer-Lozano $M$, Abenia P, Ferraz $S$, Rebage $\mathrm{V}$, Lopez-Pison J. Torticollis as a cause of consultation in neuropediatrics. Rev Neurol 1999; 29: 493-9.

13. Herbst JJ. The esophagus. In: Behrman RE, Kliegman RM, Jenson HB, eds. Textbook of Pediatrics. 16th ed. Philadelphia: WB Saunders, 2000; 1121-8. 